\title{
Herberto Helder: electronicolírica faz- se contra a carne e o tempo
}

\section{Electronicalyric makes itself trough time and flesh}

Stélio Furlan ${ }^{1}$

Universidade Federal de Santa Catarina (UFSC), Florianópolis, Santa Catarina, Brasil steliofurlan@gmail.com

Resumo: A justaposição dos excertos Electronicolírica e faz-se contra a carne e o tempo no título deste trabalho sugere um modus operandi caro à poética de Herberto Helder: a tessitura combinatória. Trata-se de um estudo sobre a poesia experimental herbertiana, que privilegia a investigação do ludismo combinatório de uma escritura não avessa à consistência estrutural, mote para a reflexão sobre instrumentos de criação e processos compositivos acionados pelo / no espaço cibernético. Palavras-chave: Electronicolírica, Herberto Helder, poesia experimental Abstract: The juxtaposition of the excerpts "Electronicolírica" and "faz-se contra a carne e o tempo" on the title of this work suggest a modus operandi precious to the poetics of Herberto Helder: the combinatory texture. It is a study of the herbertian experimental poetry that privileges the investigation of a ludic combinatory of a writing not averse to a structural consistency, motto for reflection about instruments of creation and combinatory processes activated by/on the cybernetic space.

Keywords: Electronicalyric, Herberto Helder, Experimental Poetry

Recebido em 22 de janeiro de 2014.

Aprovado em 21 de maio de 2014.

${ }^{1}$ A primeira versão deste ensaio foi publicada em meio eletrônico na revista Texto Digital, em 2006. 
Da carnagem das gramáticas arranco a música o nome o número Herberto Helder

justaposição dos excertos Electronicolírica e faz-se contra
a carne e o tempo mobiliza um modus operandi caro à
poética herbertiana: a tessitura combinatória. O primeiro sintagma alude ao título do livro de poesia experimental lançado em 1964, no qual Herberto Helder faz valer o procedimento criativo das transposições dos processos aleatório e combinatório, associados à máquina eletrônica. Já o fragmento "faz-se contra o tempo e a carne" é o verso-remate de "O poema", publicado em $O$ amor em visita (1958), ${ }^{3}$ no qual discute as condições de possibilidade do fazer poético. O poema faz-se contra o tempo: como veremos, as nuances da temporalidade se exibem condensadas nas expressões "noite", "neve", "fogo". E, contra a carne, pode sugerir tanto colado ao corpo, fonte inesgotável de percepção, quanto versus, o que sugere a ideia de que é imperativo dizer para fixar a corporeidade no instante.

Este ensaio tece algumas considerações sobre dois poemas de Electronicolírica, "A bicicleta pela rua adentro - mãe, mãe -" e "A menstruação quando na cidade passava", tomando como mote o jogo combinatório dessa poesia de invenção que não descura da consistência estrutural. É o que se pode ler numa nota posfacial de Herberto Helder sobre o que anima a sua máquina lírica:

Em 1961 Nanni Balestrini realizou em Milão uma curiosíssima experiência. Escolhendo alguns fragmentos de textos antigos e modernos, forneceu-os a uma calculadora eletrónica que, com eles, organizou, segundo certas regras combinatórias previamente estabelecidas, 3002 combinações, depois seleccionadas. O autor destes poemas aproveitou da referida experiência o princípio

\footnotetext{
${ }^{2}$ HELDER, 2000, p. 53-66. Todas as indicações de páginas entre parêntesis referidas no corpo deste artigo referem-se a esta coletânea de poemas. Vale registrar também que a escrita livre de Herberto Helder ganhou outra excelente antologia intitulada $\mathrm{Ou}$ o poema contínuo, publicada em São Paulo pela editora A Girafa em 2006.

3 “- E o poema faz-se contra a carne e o tempo". HELDER, 2006, p. 26.
} 
combinatório geral nele implícito. Assim, utilizando um limitado número de expressões e palavras mestras, promoveu a sua transferência ao longo de cada poema sem, no entanto, se cingir a qualquer regra. Sempre que lhe apeteceu, recusou os núcleos vocabulares iniciais e introduziu outros novos, que passaram a combinar-se com os primeiros ou simplesmente entre si. Devido ao uso de restrito número de palavras, as composições vinham a assemelhar-se, nesse aspecto, a certos textos mágicos primitivos, a certa poesia popular, a certo lirismo medieval. A aplicação obsessiva dos mesmos vocábulos gerava em linguagem encantatória, espécie de fórmula ritual mágica, de que o refrão popular é um vestígio de que é vestígio também o paralelismo medieval, exemplificável com as cantigas dos cancioneiros.

E arremata:

O princípio combinatório é, na verdade, a base linguística da criação poética. ${ }^{4}$

Embora a passagem seja autoexplicativa, se pode acrescentar que a metáfora do jogo calha à perfeição para perscrutar esta experiência textual, uma vez que solicita uma noção de poesia como campo no qual se favorecem "substituições infinitas no fechamento de um conjunto finito". 5 Aqui, o movimento do jogo ativa a lógica da suplementaridade no que tange à demanda de um signo que supra, que acrescenta, que "vem a mais", pois, como veremos, a escrita livre de Herberto Helder embora herdeira da grafia surreal é menos automática do que marcada por uma consciência linguística diligente. Importa, sobretudo, é a aventura da construção textual e o jogo da sua realização. Se o princípio combinatório, como defende Herberto Helder, é a base linguística da criação poética, então, glosando Derrida, todo discurso é bricoleur. No caso, o lúcido jogo textual feito de imbricações várias alude ao trabalho de bricolage: entenda-se, com Giorgio Agamben, um "trabalho intermitente" cujo processo compositivo consiste em montar novas estruturas mediante a recombinação de peças e materiais disponíveis, por extensão, um trabalho

${ }^{4}$ HELDER, 1964. Esse livro de poemas foi posteriormente renomeado com o título A máquina lírica.

${ }^{5}$ Sobre o conceito de “jogo" vide Jacques Derrida, A Escritura e a Diferença, p. 244. 
manual feito de improvisos e que aproveita "toda a espécie de materiais e objectos". 6

Nesse sentido, Herberto Helder em Electronicolírica mobiliza novas estratégias e zonas de exploração poética que instigam pela "espaçosa desarrumação das imagens" (p. 101): aí entra o ritmo insensato, o gosto centrado na variação organizada de versos-palavras e a seleção vocabular, que não raro evidenciam combinações inesperadas capazes de levar ao extravio do código legível comum.

Herberto Helder é considerado tanto um revolucionário da forma poética, nas palavras de Jorge Henrique Bastos, "desarticulador radical de toda a tradição portuguesa" cujo "abalo que sua poesia provoca é um dos mais profundos que a literatura de língua portuguesa já sofreu", ${ }^{8}$ quanto o que assegura a vitalidade da tradição da ruptura. Conforme Maria Lúcia Dal Farra, Herberto Helder é continuador da "tradição do illisible e do enoüi, na esteira de Baudelaire, Rimbaud, Mallarmé (do poema que se faz como resistência e afronta aos discursos dominantes e facilmente consumíveis), passando pelo surrealismo, pela experimentação, e exercendo-se como vanguarda permanente" ${ }^{9}$ Demais, e confesso que premido por certa angústia de influência teórica, não seria ocioso investigar em que medida a poesia herbertiana mobilizaria recursos hipertextuais, ampliando por extensão o rol de textos conforme uma tradição não-linear ou multilinear em literatura. ${ }^{10}$

Se a dita experimentação poética alude "a certo lirismo medieval", não seria errôneo afirmar que Herberto Helder suplementa a tradição da ruptura pela criação do que se pode chamar cibertrobadour. Questionador incessante do seu gesto poético, repetidas vezes justifica o que o punge: "Cantar é um subterrâneo", "o canto é o meu corpo purificado" (p.37), logo, o canto é modus

\footnotetext{
${ }^{6}$ Ver AGAMBEN, 2005, p. 172. Segundo Carlos Ceia, bricolage é um "termo francês que significa, literalmente, um trabalho manual feito de improvisos e aproveitando toda a espécie de materiais e objectos. Nas modernas teorias da literatura, o termo passa a ser sinónimo de colagem de textos ou extra-textos numa dada obra literária, o que nos aproxima da ideia de hipertexto. Também serve para traduzir uma prática dita pós-modernista de transformação ou estilização de materiais preexistentes em novos (não necessariamente originais) trabalhos". $<\mathrm{http}: / /$ goo.gl/3cYb2e $>$.

${ }^{7}$ BASTOS,2000, p. 9

${ }^{8}$ BASTOS, 2000, p. 11

${ }^{9}$ BASTOS, 2000, p. 156

${ }^{10}$ Ver PALÁCIOS, s/d.
} 
para desvelar a corporeidade do que existe e nomear o que pulsa no corpo do mundo. Assim, o eu-lírico pode dizer corpo como "objeto cantante" (p. 34) e se nomear como "uma coisa audível, sensível. / Um movimento." (p. 41).

Herberto Helder não só evoca a lírica trovadoresca na recorrência à linguagem encantatória engendrada pelo refrão popular e pelo paralelismo medieval, processos compositivos típicos dos cantares dos cancioneiros, mas também pelo campo semântico. Com efeito, tal poesia é

[...] rara pela sua qualidade de plenitude e de exuberante consumação do amor, numa literatura em que o poeta tem sido desde sempre o "desprezado" e o amor só pode ser infeliz. A maneira de Herberto Helder cria e concretiza a veemência do desejo e a força imparável de sua realização, faz com que os poemas se revistam de encadeamentos de imagens, metáforas e simples referências que destroem o discurso, mas nos dão um verbalismo vivo e válido porque tende para a recriação do caos original, para a exuberante felicidade do amor no paraíso terreal. ${ }^{11}$

Isso justifica a reiteração do encarecimento à mulher na singular ars amatória herbertiana: "são fabulosas / as mulheres" (p. 36). Contudo, não se trata mais da medieva donna inefável, conjunto de virtudes excelentes, auratizada pelo espartilho do código amoroso cortês que, via de regra, impunha ao sujeito poético a sublimação do amor em ânsia incorpórea. Ele prefere cantar, simplesmente, "uma mulher com quem beber e morrer" (p. 17). Canta "uma jovem mulher com sua harpa de sombra / e seu arbusto de sangue" (p. 17), a "mulher de ventre escarlate onde o sal põe o espírito" (p. 17), a mulher com "seus sorrisos ardendo / suas mamas de pura substância, / a curva quente dos cabelos" (p. 18).

Na poesia de Herberto Helder há um encarecimento do feminino, "Porque as mulheres não pensam: abrem / rosas tenebrosas / alagam a inteligência do poema com o sangue menstrual" (p. 48). Porque "essas mulheres tornam feliz e extensa / a morte da terra" (p. 49). E evoca a "cândida variedade das mulheres amadas" (p. 45), o "caos materno" (p. 116), a "matéria materna" (p. 141), "minha mãe, minha máquina". Leia-se:

${ }^{11}$ MENERÉS; MELO E CASTRO, 1959, p. XXI. 
A bicicleta pela rua adentro - mãe, mãe Ouvi dizer toda a neve.

As árvores crescem nos satélites.

Que hei-de fazer senão sonhar

Ao contrário quando novembro empunhaMãe, mãe - as telhas dos seus frutos?

As nuvens, aviões, mercúrio.

Novembro - mãe -com as suas praças

Descascadas.

A neve sobre os frutos - filho, filho.

Janeiro com outono sonha então.

Canta nesse espanto - meu filho - os satélites

Sonham pela lua dentro na sua bicicleta.

Ouvi dizer novembro.

As praças estão resplendentes.

As grandes letras descascadas: é novo o alfabeto.

Aviões passam no teu nome -

minha mãe, minha máquina -

mercúrio (ouvi dizer) está cheio de neve.

$[\ldots]$

Era tudo uma máquina

com as letras lá dentro. E eu vinha cantando

com a minha paisagem negra pela neve.

E isso não acabava nunca mais pelo tempo

fora. Começo a lembrar-me.

Esqueci-te as barbatanas, teus olhos

de peixe, tua coluna

vertebral de peixe, tuas escamas. E vinha

cantando na neve que nunca mais acabava.

$[\ldots]$

- mãe - nunca mais acabava pelo tempo fora.

O poema é uma membrana sensível no qual freme um ar do tempo: indicia uma relação sobredeterminada com o contexto no qual surge e que transfigura, glosando Maria Estela Guedes, autora de Herberto Helder, Poeta Obscuro (1979), a máquina lírica herbertiana é acionada à época em que os primeiros satélites chegam à Lua e o poeta não pode resistir 
à tentação do luxo do espaço: toda a área e enorme distância siderais serão arrastadas para o interior do corpo que as devora, ultrapassando pantagruelicamente os seus limites corporais. Noutras palavras, a voragem da nomeação mobiliza as energias do poema surpreendendo o nome cotidiano das coisas: é "um baptismo atónito, sim uma palavra / surpreendida para cada coisa" (p. 130).

Se o poema é uma forma recortada do mundo, como quer Herberto Helder, o que daí deriva é um fazer poético gestado pelas associações nem sempre esperadas, um convite à semiose infinda. Noutras palavras, ao visitar certos processos compositivos na vertente surreal, Electronicolírica sugere um trabalho lírico como resultado do talhe e associação por collage, caso de "A menstruação quando na cidade passava" no qual o inusitado das aproximações plasma a imagem poética. Imagem esta que se modela pela liberdade associativa e recombinatória de versos e palavras-núcleo. Nesse sentido, a imagética herbertiana verte-se tão mais intensa quanto mais inesperadas forem essas realidades (imaginadas) postas em contiguidade:

A menstruação quando na cidade passava $\mathrm{o}$ ar. As raparigas respirando, comendo figos - e a menstruação quando na cidade corria o tempo pelo ar.

Eram cravos na neve. As raparigas riam, gritavam - e as figueiras soprando de dentro os figos, com os seus pulmões de esponja branca. E as raparigas comiam cravos pelo ar.

E elas riam na neve e gritavam: era o tempo da menstruação.

As maçãs resvalavam na casa.

Alguém falava: neve. A noite vinha partir a cabeça das estátuas, e as maçãs resvalavam no telhado - alguém falava: sangue.

$\mathrm{Na}$ casa, elas riam - e a menstruação corria pelas cavernas brancas das esponjas, e partiam-se as cabeças das estátuas. Cravos - era alguém que falava assim. $\mathrm{E}$ as raparigas respirando, comendo 
figos na neve.

Alguém falava: maçãs. E era o tempo.

O sangue escorria dos pescoços de granito, a criança abatia a boca negra

sobre a neve dos figos - e elas gritavam

na sombra da casa.

Alguém falava: sangue, tempo.

As figueiras sopravam no ar que

corria, as máquinas amavam. E um peixe

percorrendo, como uma antiga palavra

sensível, a página desse amor.

E alguém falava: é a neve.

As raparigas riam dentro da menstruação, comendo neve. As cabeças das

estátuas estavam cheias de cravos,

e as crianças abatiam a boca negra sobre

os gritos. A noite vinha pelo ar,

na sombra resvalavam as maçãs.

E era o tempo.

E elas riam no ar, comendo

a noite,

alimentando-se de figos e de neve.

E alguém falava: crianças.

E a menstruação escorria em silêncio -

na noite, na neve -

espremida das esponjas brancas, lá na noite

das raparigas

que riam na sombra da casa, resvalando, comendo cravos. E alguém falava:

é um peixe percorrendo a página de um amor antigo. E as raparigas

gritavam.

As vacas então espreitando,

e nos focinhos consumia-se o lume em silêncio.

Pelas janelas os violinos

passavam pelo ar. E a menstruação nas raparigas

escorria pela sombra, e elas

gritavam e comiam areia. Alguém falava:

fogo. $\mathrm{E}$ as vacas passavam pelos violinos.

$E$ as janelas em silêncio escorriam

o seu fogo. E as admiráveis 
raparigas escutavam a sua canção, como

uma palavra antiga escorrendo

numa página pela neve,

coroada de figos. E no fogo as crianças

eram tocadas pelo tempo da menstruação.

Alimentavam-se apenas de figos e de areia.

E pelo tempo fora,

riam - e a neve cobria a sua página de tempo,

e as vacas resvalavam na sombra.

Em silêncio o seu lume escorria das esponjas.

Partiam-se as cabeças dos violinos.

As raparigas, cantando as suas crianças,

comiam figos.

A noite comia areia.

E eram cravos nas cavernas brancas.

Menstruação - falava alguém. O ar passava -

e pela noite, em silêncio,

a menstruação escorria pela neve.

“A menstruação quando na cidade passava" convida, glosando Drummond, a penetrar surdamente no reino das palavras para contemplar nos poemas escritos as mil faces secretas da palavra ocultas sob sua face neutra. Por inferência relacional, a pensar nas mil faces do sangue expelido: um rito de passagem ("E no fogo as crianças eram tocadas pelo tempo da menstruação"); e margem para o desencontro, para o amor que se abrevia, o que não vem a ser; ou ainda, por associação de rapariga, menstruação, neve, de um ato amoroso adiado, arrefecido pela força das circunstâncias.

Pode-se seguir, desdobrando a complexidade da imagética, discorrendo sobre o porquê da disseminação e recolha das expressões "rapariga", "vaca", "noite", "cidade", "menstruação". Por ora, vale constatar que em "A menstruação quando na cidade passava" é visível o festival de sensações, o intenso frenesi cromático. No corpo do poema, os versos trabalham como vasos comunicantes ${ }^{12}$ por onde desfilam um

\footnotetext{
${ }^{12}$ Alusão a Les vases comunicants, de André Breton, que parece ser a metáfora mais pertinente da reconciliação do sonho e da poesia com a vida. No caso, mais do que tecer pontes entre o sonho e a vigília haveria que abrangê-los para alcançar o ser humano em sua complexidade. Aliás, Breton escreve nos Manifestos do Surrealismo que é precisamente na resolução desses dois estados aparentemente tão contraditórios
} 
carnaval de sensações: auditivas (gritos, silêncios, cânticos), visuais (lume, sombra, fogo, sangue, neve); tácteis (pescoços de granito, sopro); gustativas (comiam figos). Há festa no intexto das sensações: gustativo e táctil (comendo figos na neve); auditivo, visual e gustativo (riam na sombra da casa, resvalando / comendo cravos); táctil, auditivo e visual:

E eram cravos nas cavernas brancas.

Menstruação - falava alguém. O ar passava -

e pela noite, em silêncio,

a menstruação escorria pela neve.

A travessia textual de Electronicolírica, como se lê nos poemas em questão, faz-se de obstáculos à legibilidade, o que a torna hermética, dificultando a (re)ordenação das referências feitas nos textos. Mas é justamente essa polissemia do texto illisible $^{13}$ que conduz à promoção do leitor. É sua errância voluntária e atenta pelo território das palavras o que anima o prazer da inteligência, pois o desafia a tornar-se partícipe do processo criativo, abrindo os poemas como janelas aos próprios sonhos despertos (rêve éveillé). ${ }^{14}$ Em consequência, o leitor, enredado nas malhas da letra, sente-se impelido a assumir a condição de decifrador dos múltiplos sentidos do texto.

Assim, para fruir o poema de Herberto Helder, melhor não aspirar à compreensão, o poema como sistema monolítico de determinações. Pretender extrair o sentido do poema a partir de um remate, uma chave-deouro condensadora do sentido, numa palavra, tentar explicá-lo, equivale a pretender ler no pouso da ave nos fios elétricos uma casual notação

que são o sonho e a vigília, numa única espécie de "realidade absoluta", o que define a surrealidade. O sonho aparece, em Breton, não mais como um resíduo desprezível nos limites obscuros entre o psíquico e o orgânico, mas um fenômeno psicológico de pleno direito. O sonho é inseparável do eu, outra modulação do eu, liga-se internamente a ele e o exprime.

${ }^{13}$ Concordo com Maria Lúcia Dal Farra quando diferencia illisible de ilegível. O illisible não é o que não permite leitura, mas oportunidade para o "extravio do código comum, a utilização deliberada de empecilhos de leitura, vincados na desculturalização e na desautomatização do sentido", por conseguinte, é capaz de "opor resistência aos discursos dominantes e de problematizar qualquer tipo de linguagem consumível" (DAL FARRA, 2000, p. 157)

${ }^{14}$ Ver RAYMOND, 1997, p. 251. 
musical. Aqui não é o poeta que se despersonaliza num "voo outro", como Fernando Pessoa, mas as próprias palavras-versos voam outras, em constante migração de sentido, e o que fica é a fruição do voo e do pouso reconfigurante, permitindo ao leitor flanar pelo corpo do poema com olhos desatentos à leitura linear sem buscas de complementação de sentido nos versos seguintes. Da seleção vocabular ao arranjo das palavras e versos dá-se a desautomatização da espera lírica habitual. Isso livra o exercício poético da tarefa de representar algo, da asfixia das convenções, pois, a rigor, importa mais o prazer do jogo textual transgressor, a lúcida ousadia da montagem, o lúdico brincar com as palavras.

Noutras palavras, se há um "código estético" nessa tessitura poética, este se baseia na representação de um espaço instável, não homogêneo, descontínuo: não se dá por continuidade, mas por deslocamentos, gerando o onírico pelo inesperado da aproximação. Como se nos mostrasse o quanto é limitada uma forma de conhecimento fundado numa estrutura sequencial e linear, o que permite a recepção de uma poesia outra fundada na exaltação das tensões contraditórias do mundo onde os nexos de causalidade se ausentam e o leitor pode reconciliar poesia e existência em liberdade.

E assim a escrita livre herbertiana inova o engenho e a arte. Inspiração, capacidade conceptiva, no recorte do léxico. Arte, na consciência artesanal, no vigor combinatório das palavras e das coisas, na consciência linguística diligente. Como disse, nessa máquina lírica algumas expressões e palavras-chave são combinadas e reiteradas e acabam por plasmar uma linguagem encantatória onde tudo se interpenetra e se corresponde:

As vacas então espreitando, e nos focinhos consumia-se o lume em silêncio.

Pelas janelas os violinos passavam pelo ar. E a menstruação nas raparigas escorria pela sombra, e elas gritavam e comiam areia. Alguém falava: fogo. $\mathrm{E}$ as vacas passavam pelos violinos.

$E$ as janelas em silêncio escorriam o seu fogo.

A meu ver, se tudo é posto em rotação - "os violinos passavam pelo ar", "as vacas passavam pelos violinos" - , é inevitável não lembrar 
do quadro de Magritte intitulado "La condition humaine" (National Gallery of Art, Washington DC), de 1933:

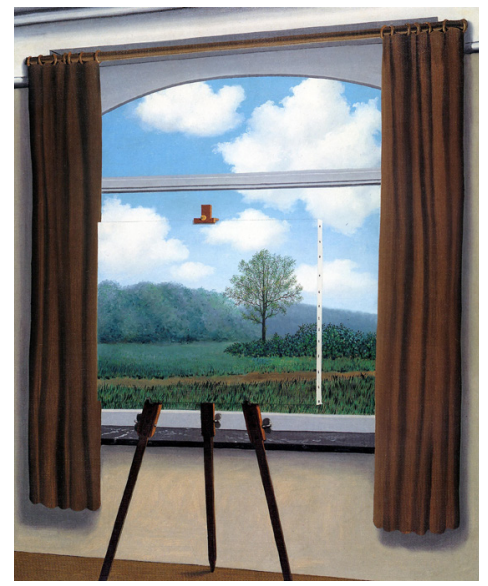

Figura 1 - La condition humaine. René Magritte (1898-1967)

Fonte: National Gallery of Art, Washington DC.

A tela simula uma janela aberta à paisagem que emoldura. É o quadro dentro do quadro, ou do que enquadra. Por inferência relacional, afora no poema em questão, também se pode ler este processo compositivo do tipo mise en abîme, nos versos de Poemacto, lançado em 1961:

- Caneta do poema dissolvida no sentido primacial do poema.

Ou o poema subindo pela caneta, Atravessando seu próprio impulso, Poema regressando. ${ }^{15}$

Mundo e poema se correspondem, mutuamente se transfundem. Nisso, o estranho prazer do texto-bricolage herbertiano parece cortejar o desejado point de l'esprit bretoniano no qual instâncias antagônicas cessarão de serem compreendidas contraditoriamente. ${ }^{16}$ Contudo, se essa

\footnotetext{
${ }^{15}$ HELDER, 2006, p. 110.

${ }^{16}$ Leia-se: "Tudo leva a crer que existe um determinado ponto do espírito donde a vida e a morte, o real e o imaginário, o passado e o futuro, o comunicável e o incomunicável, o alto e o baixo, deixam de ser apreendidos contraditoriamente. Ora, em vão procuraríamos para a atividade surrealista outro móbil além da esperança de determinação deste ponto".
} 
poesia tece associações inesperadas, a dita estratégia produtiva ultrapassa o fortuito surreal em favor de uma poesia experimental na qual predomina o nonsense do discurso desarticulado, não mais em termos surrealistas, mas por força de um consciente processo combinatório de reiteração de palavras, conferindo ao discurso uma maior consistência estrutural.

É justamente este "labor de oficina" que nos permite voltar uma vez mais à associação do poeta ao bricoleur. Claude Lévi-Strauss, em La Pensée Sauvage (1962), o define como o que utiliza "os meios à mão", ou seja, aquele que trabalha com procedimentos que acusam a ausência do premeditado, longe dos processos e normas adotados pela técnica. Opõe-se, portanto, a um tipo de conhecimento que valoriza a sistematização e o método exemplificado pela figura do engenheiro e um tipo que reverencia a improvisação sem finalidade imediata, caso do bricoleur. Vale lembrar que este conceito de bricolage foi retomado por Jacques Derrida, em "A estrutura, o signo e o jogo no discurso das ciências humanas" para esboroar a dita dicotomia entre o improvisador e o que patrocina um tipo de conhecimento privilegiando a sistematização e o método: "todo discurso é bricoleur" e "o próprio engenheiro ou sábio são também espécies de bricoleur". ${ }^{17}$

Em Herberto Helder a oposição binária suscita uma ilação problemática outra, porquanto as duas instâncias se complementam. No seu procedimento textual, o trabalho ordenado, metódico e prédeterminado do engenheiro se lê na "essência de oficina", no "trabalho linguístico vigilante", na seleção vocabular, enquanto que o labor da bricolagem é o que se ativa no giro calidoscópio (re)combinatório das palavras na máquina lírica, máquina de emaranhar percepções, visibilidades:

\section{Era tudo uma máquina} com as letras lá dentro.

Trazer à baila algo da poesia portuguesa (ainda) contemporânea, visando uma tomada de posição sobre o que há de mais expressivo e substancioso foi, por certo, uma das modestas pretensões deste ensaio. A dita textualidade suscita algum interesse aos estudos sobre uma condição hipertextual de escritura pelo processo combinatório electronicolírico que,

BRETON, 1985, p. 152.

${ }^{17}$ DERRIDA, 1971, p. 238-239. 
ao acionar poesia feita com poesia, favorece a semiòsis ilimitada. Nesse sentido, discutir a poesia herbertiana num viés hipertextual implica observar um processo criativo aberto ao movimento das conexões associativas, a possibilidade de discutir o poema como rede de múltiplas interações combinatórias (o que solicita a metáfora da teia, da trama e do tecido como conectores ou hiperligações), a problematização do compromisso do poema com a linearidade e /ou sequencialidade do verso e com desfechos conclusivos. E, em decorrência desse processo, a promoção do leitor que, em situação de perda - pois o texto-fruição de Herberto Helder, conforme a máxima barthesiana, faz entrar "em crise a sua relação com a linguagem"-, é convidado a flanar por ligações textuais diversas.

Em Electronicolírica, a leitura linear pode ser substituída por uma leitura em travessias e correlações. E se o que daí deriva incide na tradição do illisible, e se resiste à imediata compreensão e consumo, nada disso mitiga a força da expressão poética. A aleatória combinação na esteira da chamada "poesia por computador" não trava o fulgor poético-encantatório de Herberto Helder: é do esvaziamento mesmo dos conteúdos que flui o ímpeto criador capaz de excitar a nervura verbal do real. O ímpeto criador associado ao jogo de bricolagem ativado pela máquina lírica foi, como vimos, uma das constantes da poesia de Herberto Helder aqui privilegiada. Resta citar alguns versos mais à guisa de conclusão:

Folheie as mãos nas plainas enquanto desusa a gramática da madeira, obscura memória: a seiva atravessa-a.

Que a mão lhe seja oblíqua.

Aplaina as tábuas baixas e sonolentas - torne-as ágeis.

Leveza, oh faça-a como a do ar que entra nelas.

Por súbita verdade a oficina se ilude: que

de inspiração,

o marceneiro transtorne o artesanato do mundo. [...]

Tanto lavra as madeiras para que seja outro o espaço a segui-lo: [...]

- e é esse o espaço que o segue, que ele arruma, onde se põe

em equilíbrio,

nomeando os artefactos, colhendo o ar que se exala da linha de nomes sobre o abismo, e por cima do abismo ele brande aquela vara 


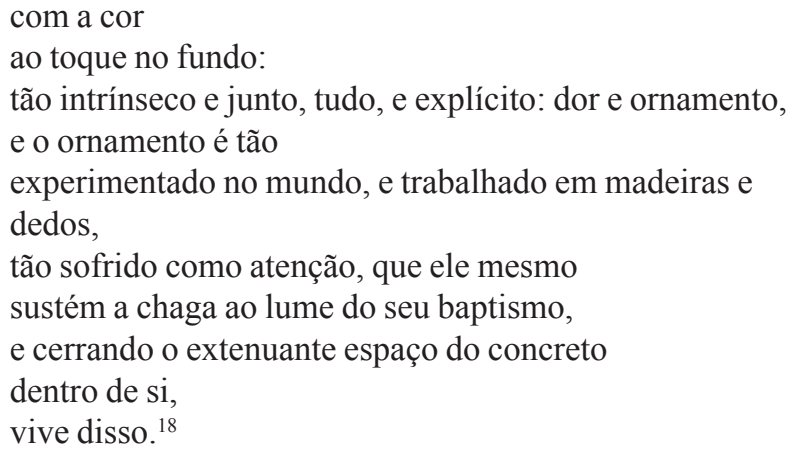

O poema se exibe como um jorro caudaloso de versos, de fragmentos de vozes seguidos de abruptos silêncios, lugar onde pausa o verso inconcluso. Na oficina herbertiana, o marceneiro-poeta nomeia "os artefactos" e transtorna "o artesanato do mundo", deste modo surpreende o poema, feito de "íngremes laborações", ${ }^{19}$ como ato de nomeação onde se canta o tempo e a carne. ${ }^{20}$

\section{Referências}

AGAMBEN, Giorgio. Infância e História. Destruição da experiência e origem da história. Belo Horizonte: Editora UFMG, 2005.

ALVES, Ida; MAFFEI, Luis. Poetas que interessam mais. Leituras da poesia portuguesa pós-Pessoa. Rio de Janeiro: Beco do Azougue, 2011.

BARTHES, Roland. O prazer do texto. Tradução de Maria Margarida Barahona. Lisboa: Edições 70, 1997.

BRETON, André. Manifestos do Surrealismo (Prefácio de Jorge de Sena). Lisboa, Moraes Editores, 1985.

BRICOLAGE. In: CEIA, Carlos (Coord.). E-Dicionário de termos

\footnotetext{
${ }^{18}$ Fragmento poético do livro de poemas intitulado Do mundo (1991-1994). HELDER, 2000, p. 138-139, grifos meus.

19 "A poesia também pode ser isso:/ a dor com que não durmo lavrado completamente/ íngremes laborações dos aerólitos - e então um pingo de ouro nos recessos / do cérebro". HELDER, 2000, p. 129.

${ }^{20}$ Ver HELDER, 1981.
} 
literários (EDTL). Disponível em: <http://goo.gl/3cYb2e> . Acesso em: 28 abr. 2014.

DAL FARRA, Maria Lúcia. "Posfacial”. In Herberto Helder: O Corpo O Luxo A Obra. São Paulo, Iluminuras, 2000.

DAL FARRA, Maria Lúcia. A Alquimia da Linguagem. Leitura da cosmogonia poética de Herberto Helder. Lisboa: Imprensa Nacional, Casa da Moeda, 1986.

DERRIDA, Jacques. A Escritura e a Diferença. Perspectiva, São Paulo, 1971.

GUEDES, Maria Estela. Herberto Helder, Poeta Obscuro. Moraes Editores, Lisboa, 1979

GUEDES, Maria Estela. Viagem e utopia em Herberto Helder. Colóquio/ Letras, Lisboa, n. 46, p. 36-45, nov. 1978.

HELDER, Herberto. A cabeça entre as mãos. Lisboa:Assírio \& Alvim, 1981.

HELDER, Herberto. Electronicolírica. Lisboa: Guimarães, 1964. (Poesia e Verdade).

HELDER, Herberto. O Corpo O Luxo A Obra. São Paulo: Iluminuras, 2000.

HELDER, Herberto. Ou o poema contínuo. São Paulo: A Girafa, 2006.

MENERÉS, Maria Alberta; CASTRO, E. M. de Melo e. Antologia da novíssima poesia portuguesa. Lisboa: Círculo de Poesia/Livraria Morais, 1959.

PALÁCIOS, Marcos. Hipertexto, fechamento e o uso do conceito de não-linearidade discursiva. s/d. Disponível em: <www.facom.ufba.br/ ciberpesquisa/palacios/hipertexto.html>. Acesso em: 27 abr. 2014.

RAYMOND, Marcel. De Baudelaire ao Surrealismo. Tradução de Fúlvia M. L. Moretto e Guacira Marcondes Machado. São Paulo: EDUSP, 1997. SILVA, João Amadeu Oliveira Carvalho da Silva. A poesia de Herberto Helder. Do contexto ao texto: uma palavra sagrada na noite do mundo. Fundação Calouste Gulbenkian - Fundação para a Ciência e a Tecnologia, Lisboa: 2004. 